\title{
Implementation of an Energy Management System in Colombian Manufacturing - A Methodological Approach
}

\author{
Juan David Marin Garcia; Juan David Marin Jimenez; and Sandra Ximena Carvajal Quintero \\ DOI: https://doi.org/10.32397/tesea.vol2.n2.2 \\ Research paper
}

Received: 15 August 2021; Accepted: 10 December 2021; Published: 15 December 2021

\begin{abstract}
This paper aims to analyze mechanisms such as the Energy management systems approach in industry 4.0. The paper is a review of techniques for optimizing energy consumption with energy efficiency, advanced metering infrastructure and rational and efficient use of energy to reduce the pollution as well as to strengthen Industry 4.0 models and the monitoring and management opportunities that exist with the implementation of this models in Colombia.
\end{abstract}

Index Terms-Advanced Metering Infrastructure, Data Analysis, Demand Management, Energy Efficiency, Energy Management System, Industrial Users.

\section{INTRODUCTION}

$\mathbf{T}$ HE industrial sector has a negative impact because it is the sector that consumes more than $30 \%$ of the energy produced globally, as well as being a prominent emitter of greenhouse gases (GHG) such as $\mathrm{CO} 2$ [1]. In Colombia, the demand for energy by industry represents a percentage greater than $20 \%$ of the total consumed throughout the country [2].

Based on the industrial projects of companies to achieve a correct transition towards industry 4.0, which refers to twoway communication between the assets of a manufacturing company such as the machinery that compose it and other equipment, with its operating personnel [3].

Industries 4.0 carry with them the fundamental principle of to send and receive mass information, through platforms that make the development of personalized applications for each of the clients benefiting from the concept a protagonist [4].

Industries 4.0 carry with them the fundamental principle of sending, receiving and advanced analysis of mass information, to achieve continuous improvement. The information is continuously obtained and stored to be reprocessed and searches for actions that must be modified to achieve better energy efficiency and operational efficiency indicators [5].

The literature analyzed shows that demand management systems that have industry 4.0 information systems generate high reductions in consumption and become active users since they participate in demand response programs. The foregoing opens possibilities for Colombia to encourage the inclusion of control and automation devices that collect information

J. Marin Garcia, Student of Master of Electrical Engineering; J. Marin Jimenez, and S. Carvajal Quintero, $\mathrm{PhD}$ in Electrical Engineering, Universidad Nacional de Colombia, Manizales, Colombia; (email: \{juadmaringar,jdmarinj,sxcarvajalq\}@ unal.edu.co) for decision-making that take full advantage of the energy potential. In addition, the creation of an energy plan that manages mining demand could create awareness regarding the rational and efficient use of energy -(URE).

The plans for the integration of industry 4.0 concepts can be analyzed from the incentive and promotion of a monitoring network between the control centers and the consumption sites, where the necessary tools would be used to make the optimization effective. of industrial systems with energy management systems (EnMS acronym in English) and energy efficiency (EE).

The recognition of the mining industry as a component of a sector of economic, social, technical and regulatory influence, generates benefits with the correct implementation of an, which provides multidisciplinary perspectives for each one of the aforementioned classifications [6].

Regarding the influence on an economic model, the investment for adaptation processes with energy efficiency principles within the industry is not low [7], since the trend is focused on the restructuring of processes such as "crushing", which is generally powered by motor machinery. Some of the financial barriers for the economic coupling are shown as the discouragement of the initial investment, the magnitude of EE projects are not sufficiently striking and a perception of risk in investment [7].

The economy of the industry focuses on the quality of its products and on the mass generation of these, in this way, the purposes of EE implementation go to the background [8].

When talking about the incidence in the social context, it is covered from an edge where the operator and the target user of EnMS have a common point of view regarding the potential of climate change, awareness is raised with EE plans, although $\mathrm{EE}$ in the sector improved over the years in industrialized countries and with the inclusion of Industry 4.0 projects, in developing countries it has not been in the same way [7].

There are various solutions on the market to capture and visualize energy consumption, as well as potential savings in the industrial sector through energy measurements [9].

Measuring the overall energy consumption of a plant is generally the only energy indicator for many industries. Carrying out consumption measurements on individual production lines leads to a costly investment in the acquisition of measurement equipment, storage systems and information processing. How- 
ever, storing records of energy consumption is not the only challenge, such consumption must be intertwined with multiple existing databases of an industry (financial, production, maintenance). Some challenges to integrate different databases in a single platform are: the uniformity of the information, loss of records, debugging of real information sources, granularity in the taking of records, among others [10].

This paper presents a methodological proposal for the implementation of an EnMS in Colombian manufacturing industries. In section II the state of the art of the transition of Industry 4.0 and its application in EnMS is presented, in section III the description of the proposed methodology is presented, in section IV a first description of the implementation in a mine factory and finally the conclusions of this paper are presented

\section{BACKGROUND}

The fourth industrial revolution, or well known as Industries 4.0, has become the result of the application of emerging technologies, included in the transition of the new paradigm for the transformation of the sector [11]. The inclusion of sets of technicians such as electronic protection devices, generation sensors, Smart Meters, AMI devices (Advanced Metering Infrastructure), network analyzers and intelligent information systems solutions (IoT, Big Data), are implemented in industries 4.0.

Despite the fact that in some industries there are technician processes, where automation techniques and optimized models are identified in their production, convergence towards structural changes in operation are typical of modernization and a specific point, which refers to the transformation towards industries 4.0, which are characteristic with cyber-physical systems [12].

The implication of Industry 4.0 makes every effort to combine smart services, smart products and smart factories, integrated collectively, where the concept of IoT (Internet of Things) and services called Internet industrial applied (IIoT), which lead to companies being sustainable [13].

Industry 4.0 applies three fundamentals: i. digitization and integration of horizontal and vertical value chains, ii. digitization of the offer of products and services and iii. innovation in digital business models [14].

One of the changes that are caused by the implementation of proprietary technologies that represent the structure of Industries 4.0 is that the systems become more complex and challenging in operation, causing it to be necessary to hire operational personnel to solve these aspects, although it has the value proposition of achieving an increase in safety, maintainability, and reliability in production processes.

The characterization of the industry in terms of its purchasing power is shown by the industrial processes it has. The foregoing refers to the fact that each industry is different and could present automatic or manual manufacturing processes or a combination of the two, called mixed. In some factories, manual and automatic intervention is required so that high quality standards are guaranteed, relative to the market [15].
Energy consumption in the industrial sector can be seen described in the behavior of three sections: time section, spatial section and user section as shown in Fig. 1 [16].

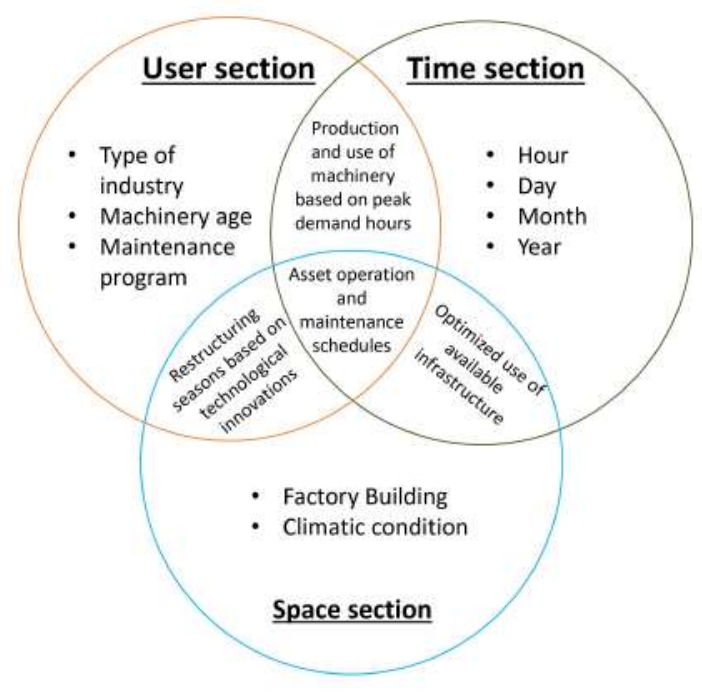

Fig. 1. Criteria for the characterization of energy consumption in industry. Adapted from [16].

Fig. 1 shows an identification of the main variables considered to carry out a characterization of energy consumption in the industrial sector is made, where their own criteria are evidenced in energy management issues, either optimization, production time bands or spaces own for the correct operation of industrial plants [16].

In the user section, key bases are identified, such as the classification of the industry by sectors, the age of the machinery, which refers to its total wear and tear, as well as keeping in mind the maintenance programs, whether corrective or preventive. In the time section, the bands in which the productive plant of a company would be in operation are enunciated and the spatial section mentions the environment on which the industry is centered and its climatic condition.

Then, a method for the analysis and characterization of energy consumption in the industrial sector is identified, based on two important aspects; the first refers to EnMS and an analysis of an ontological model focused on the management and relationship of energy-related devices, and the second refers to regulation and international success stories in the implementation of EnMS that may serve as an example fundamental for specific cases of the nation and its industrial subsectors.

\section{A. Energy Management System: A methodology for charac- terizing demand in the industrial sector}

The integration of an EnMS in the industrial subsectors, is presented as an optimized solution to implement identifiable technologies in the industry 4.0 models. The main function for an EnMS is the definition of energy flows in industrial processes, to have data to make decisions that define energy efficiency plans to optimize consumption. Within an EnMS, 
the implementation of organizational and information structures with devices, tools and mechanisms necessary for energy management is included [17].

For an analysis of the possible present problems based on energy consumption, EnMS are framed within designs with sensors that capture signals that are transmitted as data, in order to be analyzed by computer software operated by trained personnel [18].

In industry, applications for demand management are controlled in intervals or time bands of around fifteen minutes. The calculation of the common energy KPI (Key Performance Indicators), expressed as the general energy consumption and the basic energy predispositions, is due to the granularity of the data acquisition [19], through devices with specific functions such as optimizing the collection of information that must then be processed [20]. The representation of the processed data is shown in graphical interfaces after the KPIs were calculated, from data collected by new technological devices such as network analyzers and power relays [21].

In the systems used for the optimization of consumption, they include trend analysis functions, generation of diagrams and key figures that represent the electricity demand company [22].

The relationship between elements related to energy such as processes, resources and products can be represented by the ontologies within the EnMS, to have a comprehensive evaluation of the optimization of consumption with the operators and the administration of the industrialized entities. Therefore, solutions inclined towards energy efficiency are given through product data models and the consumption indicated by each unit of these. Measured consumption data can be unambiguously assigned to a product through semantics. This enables the exact resource and energy consumption of a product to be determined during the production process. In the literature, multiple methodologies are presented that allow connecting databases and information sources in real time to perform multiple analyzes that help optimize production in industries [23].

In modern information systems, representation through ontologies is used for the representation of a particular knowledge. In this sense, ontologies can integrate the relevant parts of a reality and the relationship between these parts and in this way a representation of knowledge is achieved framed within a particular context. The formal representation of concepts facilitates the mechanical reading of the knowledge stored in different databases. In this way, a context is provided to the information that can be processed with a machine. This enables man-machine communication and fosters the interconnection of available knowledge. Therefore, ontologies, as a standard for the representation of knowledge, are used in a multitude of fields of application. [23].

In the field of energy, ontologies have been used to relate the number of energy-related devices, such as machines, sensors, meters, which are associated with different process lines and allow obtaining information on the holistic performance of energy, both for the technical staff as well as administrative staff [24]. With this approach, it is possible to obtain accurate information on the main factors that can affect energy efficiency.

\section{B. Regulation to incentive the implementation of EMS and successful international experiences}

Based on the current regulation in Colombia, a diversity of criteria is used to offer incentives to users who can access demand response programs, which are related to the EnMS in terms of consumption control and optimization of the energy demanded.

Law 697 of 2001, contemplates programs to incentive the use of non-conventional energy sources as well as the rational and efficient use of energy; where it is shown to the general public that these programs are of collective interest for the convenience of the nation. In addition to this, the law determined the creation of a program for rational and efficient energy use (PROURE for the acronym in Spanish), where it was evidenced that users comply with the minimum levels of EE [25].

Law 1715 of 2014 [26] was created to promote demand response programs (DR for acronym English). The establishment of legal frameworks and instruments for the promotion of DR was the basic purpose of the aforementioned law, where the market, economic and legal barriers are gradually suppressed and overcome, creating beneficial conditions for the development of DR with EnMS [27].

On the other hand, resolution 025 of 2016 [28], allows unregulated users such as industries to participate in Voluntary Disconnectable Demand programs (DDV for the acronym in Spanish), which refers to disconnecting high consumption power plants at peak hours, to have a sustainable electrical system that guarantees the reliability and net stability network [29].

Among the successful international experiences, cases such as Spain, Italy, and China can be highlighted with demand management programs, where load disconnection contract systems were created for times or emergency states, accompanied by price programs in real-time (Spain) [30].

Also, peak power, load-displacement, load shedding programs, and high penetration of Advanced Metering Infrastructure (AMI for acronym Spanish) in Italy [30]. In China, schemes were introduced to compensate for decreased consumption in high-demand hours, also accompanied by differences in the prices of energy consumed in peak hours and off-peak hours [31].

\section{Methodology}

In this section, the methodology implemented for the development of the research is analyzed. The first step is the prediction of the demand study of industrial users. This prediction is made based on the amount of data and information accumulated in local storage units in the industry [32]. Based on the information collected, the data is managed in such a way that capture technologies, statistics, machine learning, pattern recognition, visualization methods and optimization methods are applied, among others. [33].

With the help of ontologies in the energy field, which refer to an explicit formal description of concepts within a domain 
of various opportune properties of an industrial subsector (in the present case), devices such as sensors, meters, and devices can be related. machinery in general to associate different lines of processes that allow obtaining information on the holistic performance of energy, both for technical and administrative personnel.

In Fig. 2 the basic process for the development of an energy metadata ontology is presented. This process consists of three main phases, planning, modeling and implementation, these phases accompanied by a continuous acquisition of knowledge, tests, and evaluation. The planning phase is important to analyze the field of interest and to create a complete picture as an information base on the topic of energy efficiency data in production environments [23]. The modeling phase consists of configuring the concept of ontology. The phase consists of determining tasks, such as finding terms, defining classes and their properties, and creating a class hierarchy. Finally, the model is transferred to a representation language in the implementation phase. Different tools can be used to represent the ontology, in this paper the ontology web language (OWL for acronyms English) is used as a standard, which is compatible with most systems [34].

For the design of a ontology, three fundamental rules are presented that must be constantly considered [35]:

1) There is no one correct way to model a domain. There are always multiple alternatives that depend on the application and the objective of each ontology.

2) The development of an ontology is a necessarily iterative process.

3) The concepts in an ontology should be as close as possible to the objects (physical or logical) and their relationships in the domain of their interest.

Due to the above, it is imperative to establish and identify the sources of information, the availability of databases and the degree of technological implementation of industries that will be selected according to the ease of contact with them in the region.

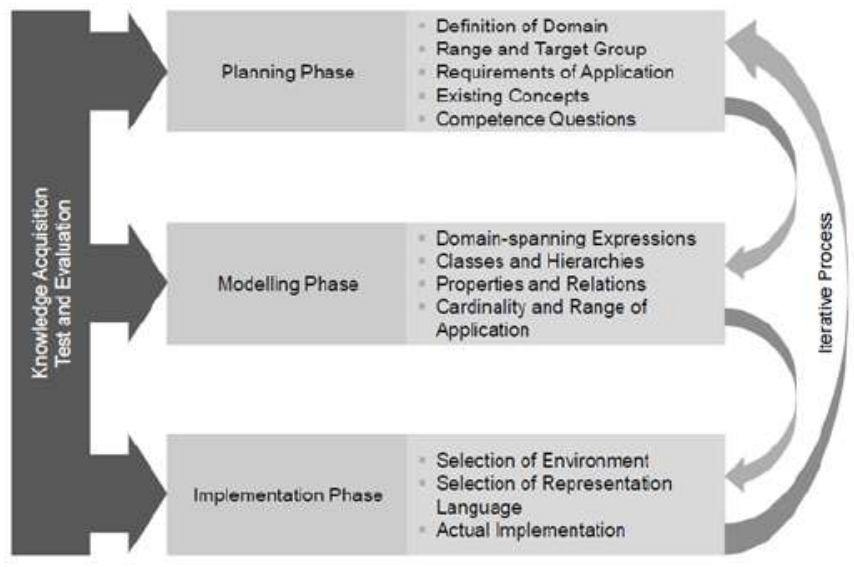

Fig. 2. Development process of an ontology. Adapted from [23].

Through the model of an ontology in an energy management system in a Mine factory it is possible to incorporate the data of the energy consumed in a production context. Additionally, correlations can be made and deviations or anomalies in energy consumption can be analyzed. To achieve an adequate model of the different actors that are part of a production process, it is necessary to have the accompaniment of a technical and administrative staff of the company to reach a consensus on the modeling. Once the main parameters, problem limits, operating conditions and objective of the model have been established, the modeling is carried out using a computational tool (OWL).

\section{STUdy CASE: COLOMBIAN GOLD MINE FACTORY}

In Colombia, there is an energy demand from the industry of $42 \%$ and the quarrying and mining sector represents $25 \%$ of the total consumed by unregulated users. With this motivation, a Colombian mining industry is selected for the proposal to implement an EnMS. In Fig. 3, the mining exploitation process of a mine factory called Gold Mine is presented. To propose an EnMS, it is important to know in detail: (i) the production process of the industry; (ii) the degree of automation or technological incorporation; (iii) existing information sources (maintenance databases, ERP, MES, PLC); (iv) the devices that deliver information (sensors, energy meters, water meters, gas meters, digital meters), and (v) field information provided by plant experts (operators, administrators, and managers).

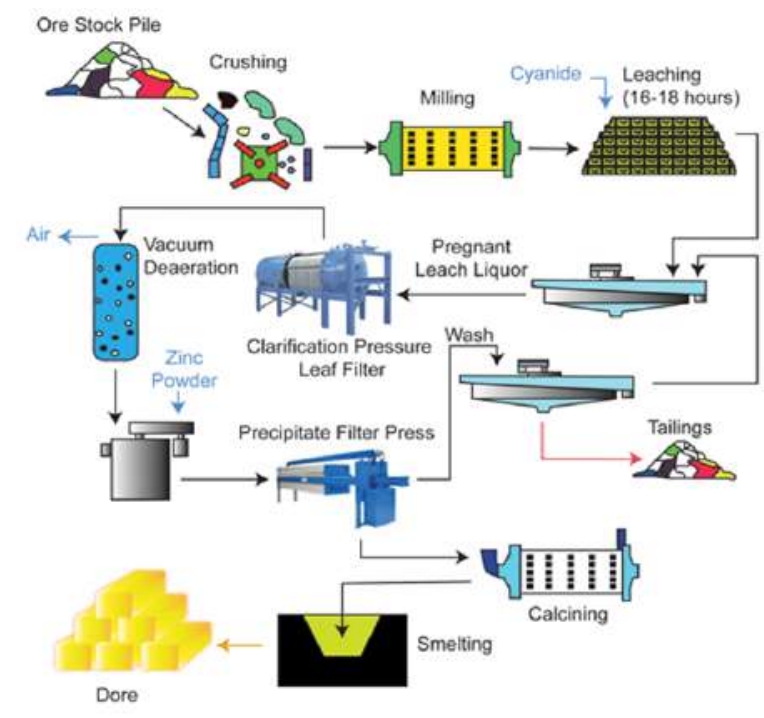

Fig. 3. Processing plant of a gold mine.

The possibilities of including EnMS that contribute to the mining industry as well as to the industry in general, are the adaptive models with EE, where the default definition for this pattern is to improve productive capacity without increasing consumption; on the contrary, decrease it [36], [37]. Based on the generalized definition, it is permissible for the sector to establish guidelines that encourage constant improvement in the productive sector of the entities to achieve goals with lower energy consumption, which represents a greater profit in the commercial framework [7], [38].

EnMS implementation helps reduce consumptions per derived unit with temporary savings [39], creation of labor and ecological benefits, since the impact on operators can influence 
the generation of research in the labor field for the planning, execution and maintenance of EnMS nested with EE programs. In Fig. 4, it is shown presents the link of the energy data of an industry with the process data that can normally be obtained. Additionally, machinery maintenance data and a representation of expert knowledge are presented.

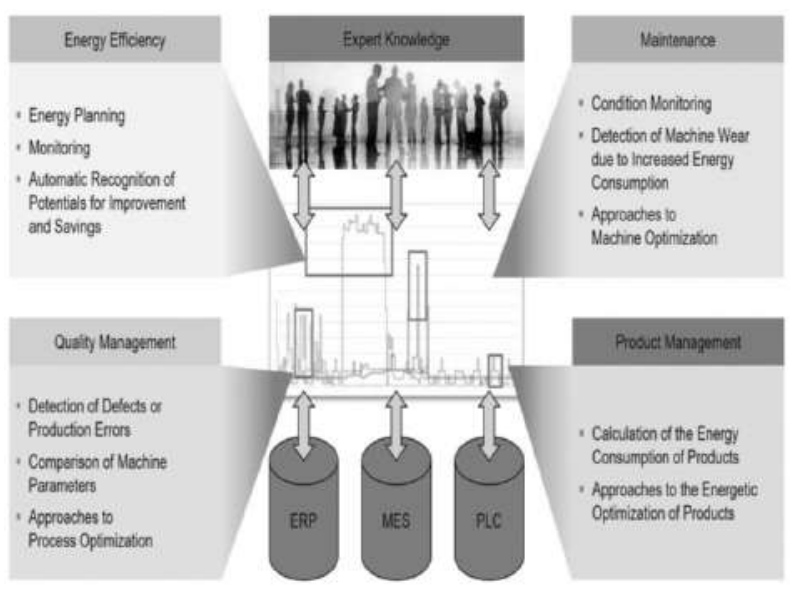

Fig. 4. The link of energy data with existing process data and knowledge pursues various objectives. Adapted from [23].

With regard to the technical field, there may be opportunities for improvement in terms of the renewal of technologies, since the problems in EE intensify when there is the presence of old machinery with high consumption, oversizing of motors, and energy losses outside the allowed limits [40]; This is how the implementation of technologies such as AMI, the acquisition of data through remote devices, monitoring and analysis of information for decision making, turns out to be a solution that implements EE through the elaboration of plans for EnMS.

To evaluate the methodology, the proposal is implemented in a production line. In particular, the selected production line has characteristics of high energy consumption and a medium degree of automation of the production process. Fig. 5 shows the main modules of the crushing production line.

Through line analysis, key tools can be identified when gathering information for EnMS modeling. Through the implementation of an ontological model, the data sources that facilitate the analysis in the correlation of the devices that make up the production line are identified. In this way, a link is made between sensors, meters and motor machinery, which strengthen the process and allow information about the holistic performance of the energy consumed, both for technical personnel and administrative personnel. In this way, it is possible to obtain detailed information about the optimal processes necessary to align energy efficiency as a fundamental principle.

\section{Conclusions}

The characteristics of industries 4.0 or the current fourth industrial revolution have generated a series of new challenges in the field of data analytics used for the optimization of manufacturing processes.

To respond to these challenges, the literature proposes the use of methodologies that make it possible to drive digital

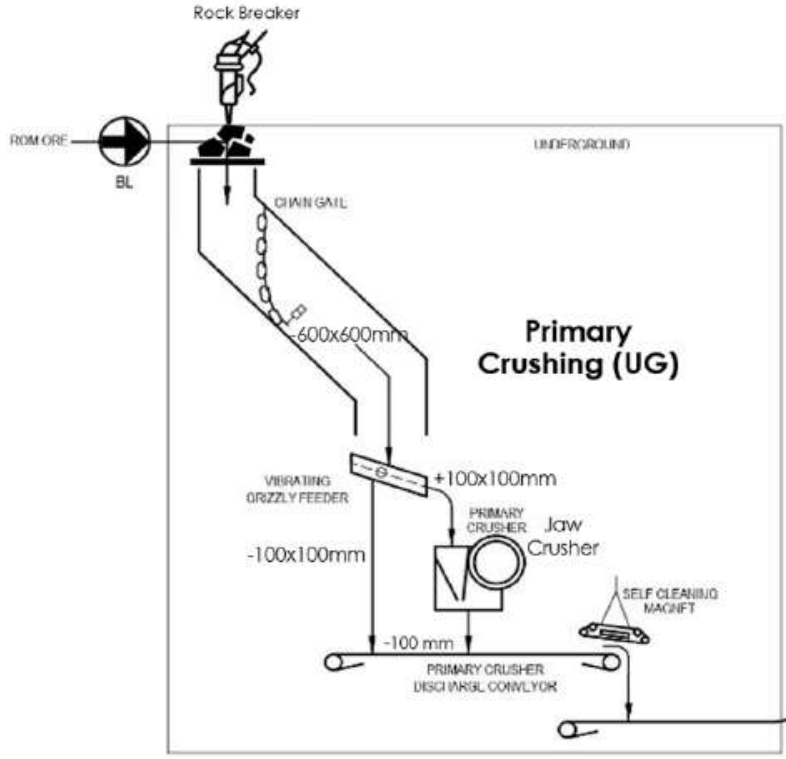

Fig. 5. Modules of a shredding production line.

data, connectivity, evaluation the consumption of each industry separately, that is, to focus on the opportunities that arise depending on the tools present in each subsector.

In this paper, the case study is a Colombian mine factory, in order to, reduce electrical consumption used to ontologies that allow approaching in between multiple intelligent systems, which include human and artificial agents.

The optimization models for a raw material transformation subsector such as iron and steel are different from those of the mining industries, although their production models may or may not be similar in terms of the type of machinery used.

Based on the ontologies, in the EnMS in the industry, it is possible to incorporate data on energy consumed in a productive context. In this way, to reach the point of consumption modeling and propose optimization techniques, correlations must be made and deviations in consumption analyzed.

Hence, this paper presents criteria and development partial that we considered important to apply in the study case, to reach the standardization effort in the factory 4.0 domain and samples of real-world scenarios.

\section{REFERENCES}

[1] L. Price, A. McKane, M. Ploutakhina, P. Monga, D. Gielen, M. Bazilian, P. Nussbaumer, M. Howells, and H.-H. Rogner, "Policies and measures to realise industrial energy efficiency and mitigate climate change," 2009.

[2] Bnamericas, "2019 cerró con crecimiento del 4.02\% en el consumo de energía en Colombia," 2020.

[3] M. de Tecnologias de la Informacion y las Comunicaciones, "Aspectos básicos de la industria 4.0," tech. rep., 2019.

[4] FENALCO, "Que aparezca la industria 4.0 en colombia," 2019.

[5] J. H. Bocanegra, "Estado de la industria 4.0 en colombia," 2017.

[6] M. de Energía y Minas de Perú, "Guía de orientación del uso eficiente de la energía y de diagnóstico energético," 2017.

[7] A. B. Nordelo, "Barriers and key factors to promote energy efficiency in industry,"

[8] G. E. G. Bustamante, "Análisis de escenarios de la gestión energética del sector industrial del ecuador," Master's thesis, 2018. 
[9] T. Javied, T. Rackow, R. Stankalla, C. Sterk, and J. Franke, "A study on electric energy consumption of manufacturing companies in the german industry with the focus on electric drives," Procedia CIRP, vol. 41, pp. 318-322, 2016.

[10] Z. Kaile, F. Chao, and Y. Shanlin, "Big data driven smart energy management: From big data to big insights," Renewable and Sustainable Energy Reviews, vol. 56, pp. 215-225, apr 2016.

[11] K.-D. Thoben, S. Wiesner, and T. Wuest, “"Industrie 4.0” and Smart Manufacturing - A Review of Research Issues and Application Examples," International Journal of Automation Technology, vol. 11, pp. 4-16, dec 2017.

[12] J. Lee, B. Bagheri, and H.-A. Kao, “"AA Cyber-Physical Systems architecture for Industry 4.0-based manufacturing systems," Manufacturing Letters, vol. 3, pp. 18-23, jan 2015.

[13] N. Carvalho, O. Chaim, E. Cazarini, and M. Gerolamo, "Manufacturing in the fourth industrial revolution: A positive prospect in sustainable manufacturing," Procedia Manufacturing, vol. 21, pp. 671-678, 2018.

[14] T. Bauernhansl, B. Diegner, J. Diemer, M. Dümmler, C. Eckert, W. Herfs, H. Heyn, C. Hilger, M. Ten Hompel, J. Kalhoff, et al., "Industrie 4.0-whitepaper fue-themen," Berlin: Bundesministerium für Wirtschaft und Energie-Plattform Industrie, vol. 4, p. 11, 2014.

[15] D. Tiwari, M. Farnsworth, Z. Zhang, G. W. Jewell, and A. Tiwari, "Inprocess monitoring in electrical machine manufacturing: A review of state of the art and future directions," Proceedings of the Institution of Mechanical Engineers, Part B: Journal of Engineering Manufacture, pp. 2035-2051, 2021.

[16] N. Koseleva and G. Ropaite, "Big data in building energy efficiency: understanding of big data and main challenges," Procedia Engineering, vol. 172, pp. 544-549, 2017.

[17] K. Walter, K. Sibylle, K. Johanna, R. Ina, and S. Silas, "Din en 16001: Energy management systems in practice. a guide for companies and organisations; din en 16001: Energiemanagementsysteme in der praxis. ein leitfaden fuer unternehmen und organisationen," Jun 2010.

[18] W. Hendro, J. Fabian, R. Sven, and J. Ovtcharova, "Energy efficiency evaluation in manufacturing through an ontology-represented knowledge base," Intelligent Systems in Accounting, Finance and Management, vol. 21, no. 1, pp. 59-69, 2014.

[19] B. Markus, E. Norbert, W. Daniel, and F. Jörg, "Transparent acquisition and processing of energy data in the field of industrial productionrequirements and applications," in Applied Mechanics and Materials, vol. 882, pp. 81-89, Trans Tech Publ, 2018.

[20] Exellios, "S373-Cellular Modbus MQTT IoT Gateway - Exellios IIoT Industrial Internet Of Things," 2020.

[21] B. Markus, S. Franziska, K. Sven, and F. Jörg, "Ontology-based description of energy optimization potentials for production environments," in Applied Mechanics and Materials, vol. 805, pp. 53-60, Trans Tech Publ, 2015.

[22] T. Walter, T. Tullio, and U. Marcello, "A virtual factory approach for in situ simulation to support production and maintenance planning," CIRP Annals, vol. 64, no. 1, pp. 451-454, 2015.

[23] B. Markus, B. Matthias, and F. Jörg, "Semantic meta model for the description of resource and energy data in the energy data management cycle," in Applied Mechanics and Materials, vol. 871, pp. 69-76, Trans Tech Publ, 2017.
[24] M. Imadeddine, O. Brahim, H. Ferdaous, and F. Bouchra, "Semanticbased big data integration framework using scalable distributed ontology matching strategy," Distributed and Parallel Databases, pp. 1-47, 2021.

[25] Congreso de Colombia, "Ley 697 de 2001 Nivel Nacional," 2001.

[26] Congreso de la República, "Ley 1715 de 2014," may 2014.

[27] Unidad de Planeación Minero Energética UPME, "Guia práctica para la aplicación de los incentivos tributarios de la Ley 1715 de 2014," Ministerio Minas y Energia, vol. 1, p. 28, 2014.

[28] Comisión de Regulación de Energía y Gas, "CREG 025 de 2016," tech. rep., CREG, Bogotá D.C., mar 2016.

[29] J. Hernández Vidal, "DEMANDA DESCONECTABLE VOLUNTARIA - DDV - https://estudiolegalhernandez.com," aug 2020.

[30] T. Jacopo, H. M. G, and L. Matthew, "Demand response experience in europe: Policies, programmes and implementation," Energy, vol. 35 , no. 4 , pp. 1575-1583, 2010.

[31] T. Ye, X. Fei, and C. Lei, "Research into possibility of smart industrial load participating into demand response to supply the power system," in CICED 2010 Proceedings, pp. 1-5, IEEE, 2010.

[32] W. Xin, L. Xinmin, Q. Dandan, W. Yu, L. Li, and Z. Liang, "Prediction of industrial power consumption and air pollutant emission in energy internet," in 2021 3rd Asia Energy and Electrical Engineering Symposium (AEEES), pp. 1155-1159, IEEE, 2021.

[33] A. Tenkorang, Richard, and H. Petri, "Big data applications in operations/supply-chain management: A literature review," Computers \& Industrial Engineering, vol. 101, pp. 528-543, 2016.

[34] B. Haarmann, Ontology On Demand: Vollautomatische Ontologieerstellung aus deutschen Texten mithilfe moderner Textmining-Prozesse. epubli, 2014.

[35] N. Natalya, M. Deborah, et al., "Ontology development 101: A guide to creating your first ontology," 2001.

[36] GCF (Green Climate Fund), "Eficiencia energética para la industria y los aparatos eléctricos," tech. rep., Green Climate Fund, 2017.

[37] D. Sevilleja Aceituno, "Eficiencia energética en el sector industrial," tech. rep., Universidad Carlos III de Madrid, Leganés, dec 2011.

[38] L. Biaou, P. Langlois, and J. Chabchoub, "Guía B: Justificación de la intervención del gobierno en el mercado de eficiencia energética Publications," 2012

[39] Organización Internacional de Normalización, "ISO 50001: Sistemas de Gestión de la Energía," 2011.

[40] C. C. Andrés, D. Wim, D. Johan, and P. Jhon, "Determining electrical loss in electromagnetically-modelled induction motors using the finite element method," Ingeniería e Investigación, vol. 28, no. 3, pp. 64-74, 2008.

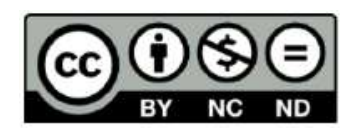

C2021 by the authors. Licensee TESEA, Cartagena, Colombia. This article is an open access article distributed under the terms and conditions of the Creative Commons Attribution (CC BY) license (http://creativecommons.org/licenses/by/4.0/) 